\title{
Is the use of contraceptives associated with periodontal diseases? A systematic review and meta-analyses
}

\author{
Micaele Maria Lopes Castro ${ }^{1}$, Maria Karolina Martins Ferreira', Iasmin Encaua Essashika Prazeres', \\ Paula Beatriz de Oliveira Nunes ${ }^{1}$, Marcela Baraúna Magno ${ }^{2}$, Cassiano Kuchenbecker Rösing ${ }^{3}$, \\ Lucianne Cople Maia ${ }^{2}$ and Rafael Rodrigues Lima ${ }^{1 *} \mathbb{C}$
}

\begin{abstract}
Background: Previous studies indicated an impact of hormonal contraceptive use on oral health. This systematic review aimed to investigate the evidence supporting the impact of the use of hormonal contraceptives and periodontal diseases.

Methods: This study is based on Preferred Reporting Items for Systematic Reviews and Meta-Analyses (PRISMA) and based on the PECO acrostic. Inclusion criteria comprised observational studies including women (P), which evaluated hormonal contraceptive users (E) and hormonal contraceptive non-users (C), to verify the association between this hormonal therapy and the periodontal diseases $(0)$. Searches were performed on 5 databases: PubMed, Scopus, Web of Science, Cochrane Library, LILACS and grey literature (OpenGrey and Google Scholar). After the selection process, the included studies were evaluated qualitatively. Moreover, quantitative data were analyzed in two meta-analyses for clinical attachment loss (CAL) and probing depth (PD). Finally, the level of certainty was measured with the GRADE (Grading of Recommendations Assessment, Development, and Evaluation) tool between periodontal clinical parameters.
\end{abstract}

Results: 18 articles were eligible for the qualitative synthesis and 7 of them were selected for quantitative analysis. Hence, 15 of the eligible articles reported an association between the use of hormonal contraceptives and severity of periodontal disease. However, 6 articles demonstrated high risk of bias and were excluded from quantitative synthesis. The meta-analysis showed a statistically significant difference for CAL (MD $0.24[0.09,0.40]$; $p=0.002$ ), but in PD (MD $0.05[-0.05,0.15] ; p=0.33)$ such difference was not identified. A very low level of evidence was found between the clinical parameters.

Conclusions: The use of hormonal contraceptives may be associated to severity of periodontal diseases. However, the quantitative analysis points to an inconclusive outcome due to the high level of heterogeneity. The association is biologically plausible, however additional studies are warranted to better elucidate the clinical significance of this possible association.

Keywords: Hormonal contraceptives, Periodontal disease, Periodontium, Systematic review

*Correspondence: rafalima@ufpa.br

${ }^{1}$ Laboratory of Functional and Structural Biology, Institute of Biological Sciences, Federal University of Pará, Augusto Corrêa street, n 1, Guamá, Belém, PA 66075-110, Brazil

Full list of author information is available at the end of the article

\section{Background}

Hormonal contraceptives are drugs used to prevent pregnancy that can also be used in specific situations as family planning, menstrual cycle regularization, reduction in 
the incidence of ovarian cysts, etc. [1]. Among the hormonal contraceptive alternatives, there are many birth control options including contraceptive pills, contraceptive patches, implants, injections, intravaginal, and intrauterine delivery. Generally, in the composition of each contraceptive drug, there are two synthetic hormones, estrogens and progestins, which act by performing selective inhibition of pituitary function $[1,2]$.

This mechanism of action generates the pituitary secretion inhibition of luteinizing hormone and follicle stimulating hormone, resulting in the hindrance of ovum release by ovary, promoting contraception [3]. However, despite the benefits, the use of hormonal contraceptives, mainly orally, is associated with systemic adverse effects, as thromboembolic and cardiovascular complications [4].

Periodontal disease in the initial phase is restricted to gingival tissues. On the other hand, in an advanced phase, this condition affects periodontal support tissues, and is called periodontitis [5]. For diagnosis of periodontal diseases, clinical measurements are used with several standardized indexes by the scientific literature which has the goal to reflect the etiology and pathogenesis of periodontal disease [6].

In the oral cavity, this relationship has been associated with periodontal status, because the sexual steroids play significant roles in modulating inflammatory response of periodontal tissues and may alter the response to oral these structures during different phases of life, including puberty, menstruation, pregnancy, menopause and postmenopausal [7-10].

Although there is a systematic review published with a similar scope [11], doubts still persist regarding the methodological quality of the published articles, as well as an integrated analysis by a meta-analysis combining the results of the selected articles. In addition, the analysis of the certainty of evidence which enables guidance on clinical decision-making process.

In this context, the present systematic review aims to investigate the scientific evidence that supports the clinical observations related to the association between the use of hormonal contraceptives and periodontal diseases.

\section{Methods}

\section{Protocol and register}

This systematic review was registered on PROSPERO under the code CRD42018115606 and was developed according to Preferred Reporting Items for Systematic Reviews and Meta-Analyses (PRISMA) and the Cochrane Protocol for systematic reviews (Additional file 1: Table S1). [12].

\section{Focused question and selection criteria}

To perform this review, the following focused question was raised: "Is there an association between the use of hormonal contraceptives and periodontal diseases?". To answer this focused question, the PECO strategy was used: observational studies in adult women (P), hormonal contraceptive users $(E)$ and non-hormonal contraceptive users $(C)$ that were evaluated to identify the presence or absence of the association between the use of hormonal contraceptives and outcomes related to periodontal diseases $(\mathrm{O})$. Pilot studies, case reports, descriptive studies, review articles, opinion articles, technique articles and guidelines, studies investigating the use of barrier contraceptives, and studies which do not report on the clinical parameters of periodontitis were discarded.

\section{Search strategy}

Searches were performed on the following electronic databases: Pubmed, Scopus, Web of Science, LILACS and Cochrane Library. Google Scholar and The Open Grey were used as gray literature sources. No restriction of year or language were applied. The search strategy was composed by MESH and entry terms and adapted according to each database, using boolean operators (OR, AND) to combine the searches. The MeSH terms used included "Contraceptives, oral, hormonal" or "Contraceptive Agents" or "Contraceptive Agents, Female" or "Contraceptives, Oral" or "Contraceptives, Oral, Sequential" or "Vaccines, Contraceptives" or "Reproductive Control Agents" and "Periodontal Diseases" or "Gingivits" or "Periodontium" or "Gingiva" or "Alveolar Process" or "Periodontitis" or "Chronic Periodontitis" or "Periodontal Attachment Loss" or "Alveolar Bone Loss" or "Oral Health" (Additional file 2: Table S2).

Manual search was also performed. It is an important complementary step to find possible eligible studies that may not have been recovered in the search strategy. This step was carried out in two ways, during the search in the bibliographic references of each selected study or in classic literature reviews and systematic reviews previously published with similar themes.

The searches were performed until December 2019. Although, a search alert was created in each database to notify new studies according to the outlined search strategy. After the searches, the citations found in each database were exported to a reference manager (EndNote ${ }^{\circledR}$, version X7, Thomson Reuters, Philadelphia, EUA). Articles indexed in more than one database were considered only once.

All evaluations, including the searches, studies selection, risk of bias evaluation, data extraction was performed in pairs, independently, by two examiners (MMLC and PBON). After each analysis, MMLC and 
PBON met to discuss the encountered data. Any disagreement between the examiners were resolved by a third reviewer (MKMF).

\section{Studies selection process}

After the importation to a reference manager, the duplicated results were removed (EndNote ${ }^{\circledR}$, versão X7, Thomson Reuters), both automatically and by manual review. Subsequently, the articles were excluded by titles and abstracts, and after for full-text reading according to the PECO's strategy within the eligibility criteria.

Moreover, the lists of references from each included article were also researched manually in order to find additional studies that could be included in the review.

\section{Data extraction}

For each selected manuscript, the following information was collected: author, country, publication year, study design, age, sample size, type of hormonal contraceptive, statistical analysis and main results. The authors of the studies were contacted if relevant data were absent in the articles.

\section{Quality analysis and risk of bias}

The guidelines proposed by Fowkes and Fulton [13] were used used in this systematic review to evaluate the quality and risk of bias of the included studies in order to verify wheter the methods and research results were sufficiently valid to produce useful information [13].

\section{Quantitative analysis (meta-analysis)}

The data of each study included in quantitative synthesis were analyzed in Review Manager (versão 5.2) to evaluate the association between the use of hormonal contraceptives and the presence of periodontal diseases.

The studies that reported results using the same methods were intended to meta-analyses. Then, the mean difference (MD), with a confidence interval of $95 \%$ (IC) was calculated. Only studies with low risk of bias were included in the meta-analysis. If any information needed for the meta-analysis was missing from any of the selected studies, the authors were contacted to provide the missing data. [14].

The heterogeneity was tested by the $\mathrm{I}^{2}$ index and, if possible, sensitivity analyzes were performed to estimate and verify the influence of the studies, one by one, on the subgroup and pooled results, when the heterogeneity was substantial or considerable (50-100\%) [15]. Two periodontal clinical parameters were included in these meta-analyses: CAL and PD. These clinical parameters allow assessing the level clinical inflammation as a result of periodontal disease (PD) as well as the changes related to the supporting periodontal tissues (CAL) [16]. Currently, those parameters have been established as the gold-standard for diagnostic of patients with periodontal diseases [17].

\section{Level of evidence: grading of recommendations assessment, development, and evaluation (GRADE)}

To evaluate the certainty of evidence among the studies, the GRADE tool [18] was applied using the following periodontal parameters: CAL and PD. The included articles were evaluated according to study design, risk of bias, inconsistency, indirectness and imprecision.

The certainty of the evidence (certainty in the estimates of effect) was determined for the outcome using the Grading of Recommendations Assessment, Development and Evaluation (GRADE) approach [18].

\section{Results}

\section{Included studies}

A total of 1231 articles were identified through the search for databases and grey literature. Then, 531 articles were excluded after duplicates removal, resulting in 700 articles. Among them, 620 were excluded after reading the titles.

From these remaining articles, 80 articles were excluded after their abstract reading, and 55 studies were eliminated, the remaining 25 articles for full-text reading to be evaluated according to eligibility criteria. Finally, 7 were excluded for the following reasons: animal study (1), review (3), interventional study (1), conference summary (1) and case report (1). Thereby, 18 articles met the inclusion criteria and were selected for qualitative synthesis [19-36]. From these, 5 articles were directed to the quantitative analysis [19, 24, 31, 32, 36] (Fig. 1).

\section{Description of study characteristics}

According to study design, fifteen are classified as casecontrol studies $[19-25,27-29,31-34,36]$ and three as cross-sectional [26, 30, 35]. The type of hormonal contraception mostly used was oral administration (present in fifteen studies). Seck et al. [34] included three types of hormonal contraception, examining patientes that used oral (Lo-Femenal ${ }^{\circledR}$ ), injectables (Depo-Provera ${ }^{\circledR}$ ), and implants $\left(\right.$ Norplant $\left.{ }^{\circledR}\right)$. The study of Tilakaratne et al. [36] analyzed the injectable and oral contraceptive users, while Kazerooni et al. [30] evaluated only implant contraceptives of Levonorgestrel. All the studies performed clinical analyses of periodontal condition (Table 1).

\section{Quality assestment and risk of bias}

Furthermore, after a detailed evaluation of methods and results, the studies were analyzed to verify the possibility 


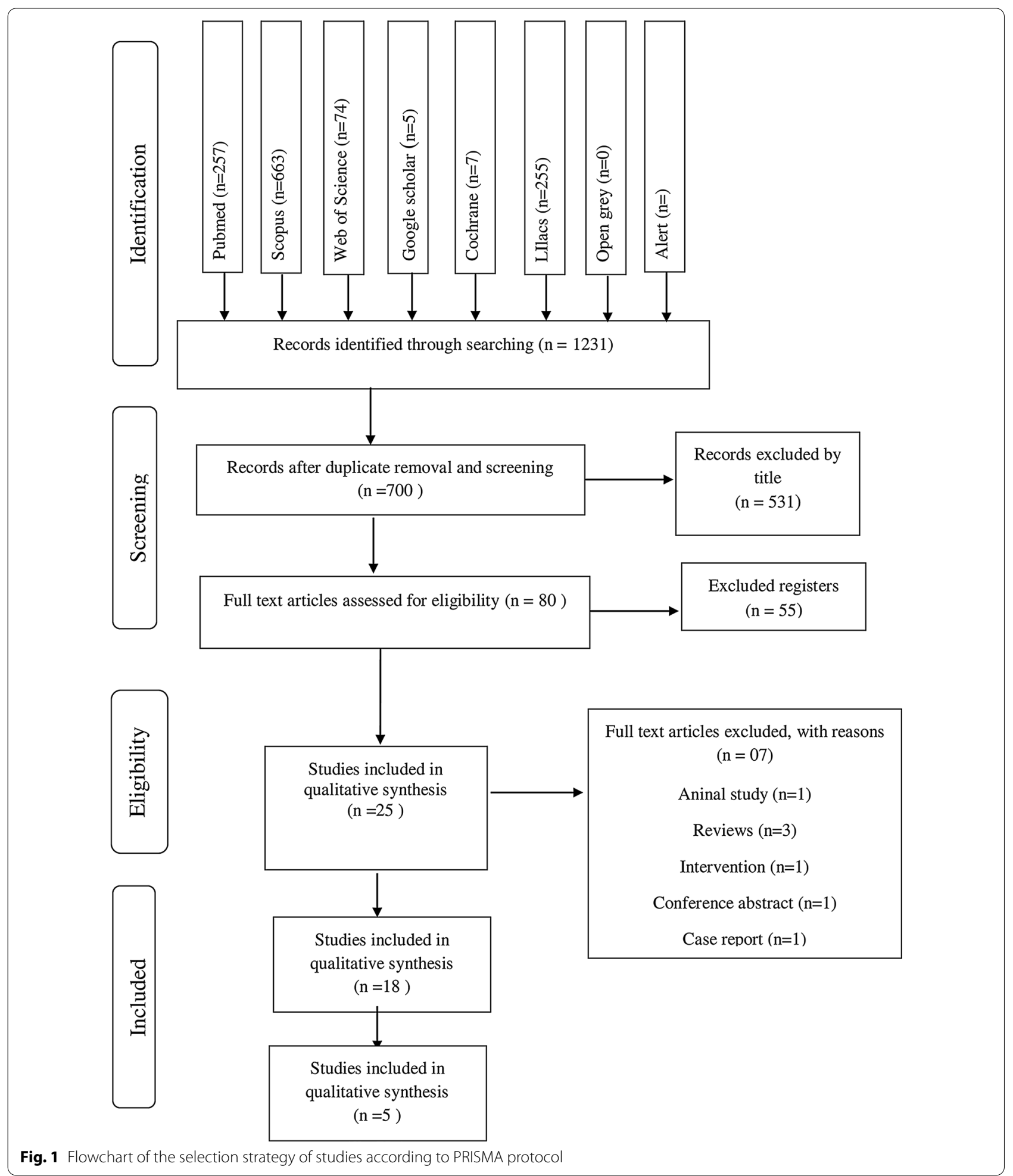

of "biased results", "confouding" and "occurrence by chance" (Table 2). Four studies were classified with high risk of bias $[23,27,28,30]$. The major problems observed were in relation to the sample (sample size and definition of inclusion and exclusion criteria) and the acceptability of the control group (absence of description of the randomization/correspondence process). 
Table 1 Domains and risk of bias according to Fowkes and Fulton

\begin{tabular}{ll}
\hline Guidelines & Checklist \\
\hline Study design appropriate to objectives? & Objective common design \\
& Prevalence Cross-sectional \\
& Prognosis Cohort \\
& Treatment Controlled trial \\
& Cause Cohort, case-control, cross-sectional \\
Study sample representative? & Source of sample
\end{tabular}

Sampling method

Sample size

Entry criteria/exclusion

Non-respondents

Control group acceptable?
Definition of controls

Source of controls

Matching/randomization

Comparable characteristics

\section{Description}

The type of study was marked in the appropriate type of study. If the type of study was appropriate according to the study design, it was labelled as "0", and as "++" if it was not appropriate

The domain was considered [0] in cases of detailed origin, [+] to a specified origin of only one group and $[++]$ in cases of absence of specification of the source of the groups

The item was assigned [0] for a full description of sampling method, [+] for poor or no explanation of sample method, with no problem in matching between groups, and $[++]$ for poor or no description of sample method, interfering in the matching of the groups

A minor problem $[+]$ was considered when the sample was not representative or did not report a sample calculation. To a major problem, $[++]$ was considered when no sample calculation was provided, and the number of participants was less than 50 participants, [0] was considered in the absence of the above factors

A minor problem [+] was attributed when the control and case group reported current use of antibiotics or anti-inflammatories, diabetes, smoking or pregnancy. In the case of presence of more than two previously mentioned items, it was considered as a major problem $[++]$

The [0] was attributed when there was no refusal to participate in the study, [+] was assigned when there was the refusal, but did not compromise the sample, and $[++]$ when there were refusal and impairment of the sample size

It was attributed [0] when all characteristics of the control group were described, [+] when any information was pendent as the origin of the control group, the selection criteria and a different origin between case and control groups and $[++]$ when two or more items described in previously items

It was considered [0] when the control group was referred, $[+]$ when the origin of groups was different, but with reasons and $[++]$ when the groups presented different origins without reasons

In this item, [0] was assigned to cases of randomized/ matched groups, [+] to cases of no description of randomization, but with a matching of groups and $[++]$ to no explanation of randomization or matching

It was attributed [0] to matched groups or not matched by the impossibility of being subsequently adjusted and $[++]$ the presence of unpaired variables that were not paired or adjusted 
Table 1 (continued)

Guidelines Checklis

Quality of measurements and outcomes? Validity

Reproducibility

Blindness

Quality control

Completeness

Compliance

Dropouts

Deaths

Missing data

\section{Description}

It was considered [0] when the evaluation method applied is appropriate; $[+]$ when using a single method, but with appropriate sensitivity with good specificity; $[++]$ when using a single method, without an adequate specificity or good sensitivity

It was considered [0] whether the evaluation methods were well described; $[+]$ when a lack description of any step of the method was presented, for example, the identification of the patients of the groups studied in laboratory samples, evaluations at different times or application of various methods between groups of individual pathology; $[++]$ when two or more of the previous items are present

The condition of the study participants was considered to be "Blind," in this case being assigned the signal [0], in cases of "not blind" the signal $[++]$ was attributed

It was considered a problem when the examiner was not qualified; a partial periodontal exam was performed [not in all teeth or not in all the six periodontal sites/teeth], the measurement of periodontitis was only radiographic or the absence of the number of evaluated teeth sites. A Minor problem [+] was considered when 2 of these characteristics were present, and a major problem $[++]$ if more than 2 of these characteristics were present

It was assigned [0] for a sample size that remains the same from the beginning to the end or decreases without compromising the power of the test; $[+]$ for differences in sample size at the end of the study, compromising the power of the test, but with reasons and adjusts; $[++]$ for difference in sample size at the end of the study, compromising the power of the test, without reasons

The [0] was scored when there is no loss during the study, [+] when there is a withdrawal that involves the inclusion criteria, such as age, sex, $[++]$ when there is withdrawal and it compromises more than one criterion

This item was scored as Not Applicable [NA], due to the type of PECO strategy

In this item, [0] was assigned to cases of randomized/ matched groups, [+] to cases of no description of randomization, but with a matching of groups and $[++]$ to no description of randomization or matching 
Table 1 (continued)

\begin{tabular}{|c|c|c|}
\hline Guidelines & Checklist & Description \\
\hline \multirow[t]{5}{*}{ Distorting influences? } & Extraneous treatments & $\begin{array}{l}\text { In this item, [0] was considered when there were no } \\
\text { external influences; }[+] \text { when there are external } \\
\text { influences, but that does not interfere in the results; } \\
{[++] \text { when there are external influences and inter- }} \\
\text { feres with the results }\end{array}$ \\
\hline & Contamination & $\begin{array}{l}\text { This item was scored as Not Applicable [NA], due to } \\
\text { the type of PECO strategy }\end{array}$ \\
\hline & Changes over time & $\begin{array}{l}\text { In this item, }[0] \text { was attributed to data collected in the } \\
\text { same period; }[+] \text { to data obtained from the control } \\
\text { group and the study group at different times that } \\
\text { may cause distortions; }[++] \text { when the previous } \\
\text { item was associated with data from studies already } \\
\text { published }\end{array}$ \\
\hline & Confounding factors & $\begin{array}{l}\text { A problem was assigned when the data analysis } \\
\text { involved enrollment of persons }<5 \text { years. Menopau- } \\
\text { sal woman, smokers, diabetics and obese. A minor } \\
\text { problem }[+] \text { was assigned when } 1 \text { or } 2 \text { of these } \\
\text { characteristics were present and a major problem } \\
{[++] \text { if there were } 3 \text { or more }}\end{array}$ \\
\hline & Distortion reduced by analysis & $\begin{array}{l}\text { It was considered [0] when it cites the adjustments } \\
\text { of the covariates that present distortions; }[+] \text { when } \\
\text { the article report adjustment, but does not say } \\
\text { the criteria; }[++] \text { when distortion was identified, } \\
\text { without adjustment }\end{array}$ \\
\hline \multirow[t]{2}{*}{ Summary questions } & $\begin{array}{l}\text { Bias: Are the results erroneously biased in a certain } \\
\text { direction? } \\
\text { Confounding: Are there any serious confusing or } \\
\text { other distorting influences? }\end{array}$ & \multirow[t]{2}{*}{$\begin{array}{l}\text { YES or "NO" answers were assigned to each question. } \\
\text { If the answer is NO to the three questions, the arti- } \\
\text { cle is considered reliable, with low risk of bias }\end{array}$} \\
\hline & $\begin{array}{l}\text { Chance: Is it likely that the results occurred by } \\
\text { chance? }\end{array}$ & \\
\hline
\end{tabular}

In relation to the sample source, Domingues et al. [23] and Grower et al. [27] selected lower maximum age group making the sample unrepresentative, which was considered a major problem. In relation to the sampling method, Domingues et al. [23], Vijay et al. [24], Pankhurst et al. [33] and Grower et al. [27], didnot report how the sample selection was calculated/achieved, and this was considered a major problem. Farhard et al. [19], Domingues et al. [23], Mullally et al. [32], Tilakaratne et al. [36], Jensen et al. [28] and Grower et al. [27], did not perform the sample calculation and the samples were not enough to demonstrate a significant result. Vijay et al. [24], Kazerooni et al. [30], Jensen et al. [28] and Grower et al. [27], did not describe the exclusion criteria used in the selection of the study sample, which was considered a major problem. All included articles presented problem with blindness in the measurement of the outcomes. Knight et al. [31], Kazerooni et al. [30] and Grower et al. [27], did not mention confounding factors being considered a major problem. In summary, the quality assessment of all the included articles can be found on Table 3.

\section{Meta-analysis and level of evidence}

The meta-analyses results were presented separately for each periodontal parameter. The random effect model was used since the studies were not equivalent. This strategy had the objective to generalize the results of the meta-analyses.

Five studies which evaluate CAL were included in this analysis [19, 24, 31, 32, 36]. Including all the articles, the heterogeneity was considerable $\left(\mathrm{I}^{2}=96 \%\right)$. Contraceptive users $(n=197)$ had a mean CAL greater than the control group $(\mathrm{n}=200)$ (MD 0.24 [0.09, 0.40]; $p=0.002$ ) (Fig. 2) with very low certanty of evidence (Table 4). The inclusion of high risk of bias study did not change the effect significante (MD $0.15[0.05,0.24]$ $p=0.002$ ).

Considering probing depth (PD), three studies were included in the analysis [19, 32, 36]. Including all articles, the heterogeneity was considerable $\left(\mathrm{I}^{2}=97 \%\right)$. Contraceptive users $(n=91)$ had a mean PD greater than those who did not use it $(\mathrm{n}=89)$ (MD $1.15[-0.29$, 2.59]; $p=0.12$ ) with very low certanty of evidence (Table 4). This data can be elucidated by the result of no difference between the groups in the study performed 


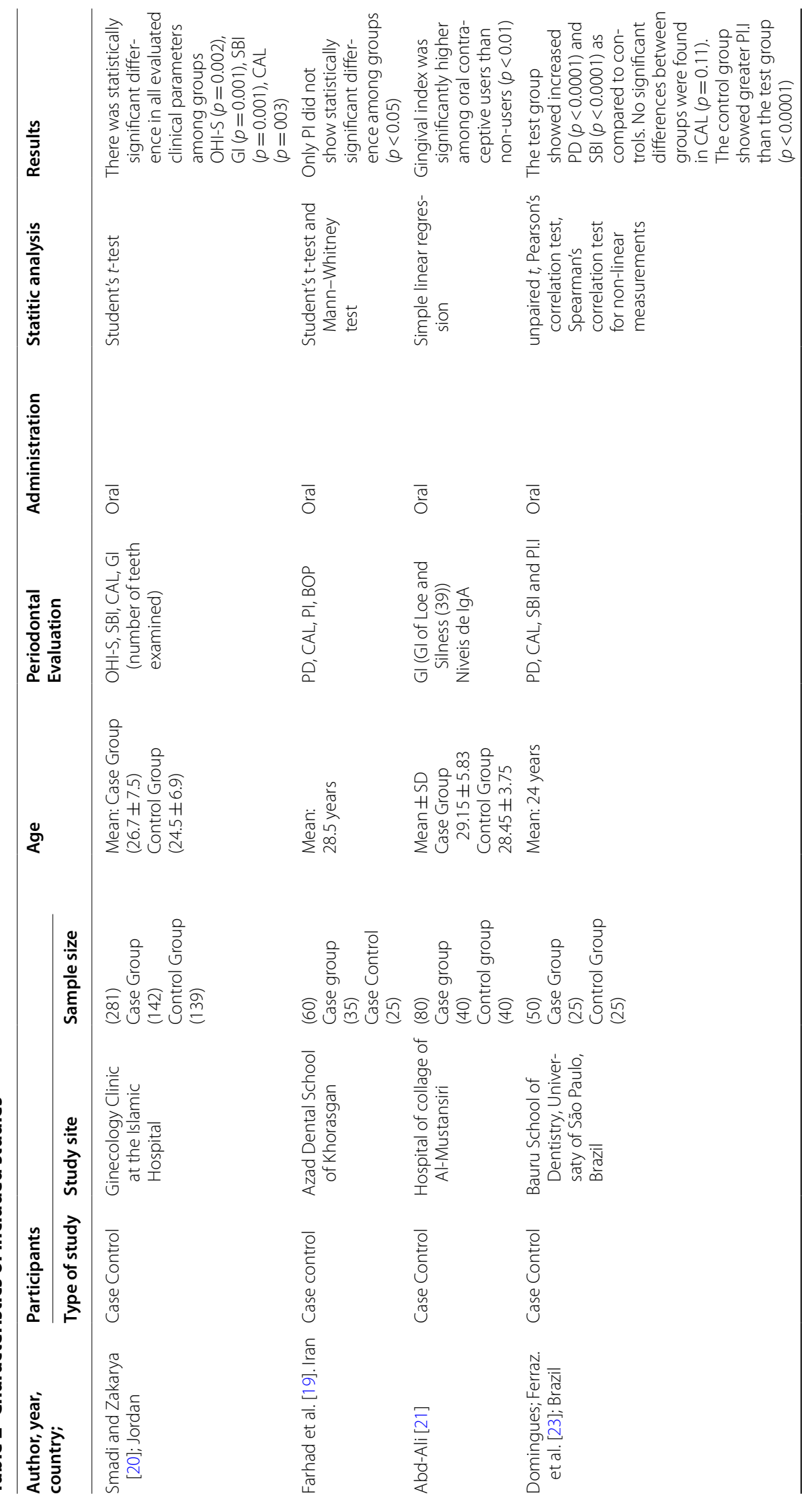




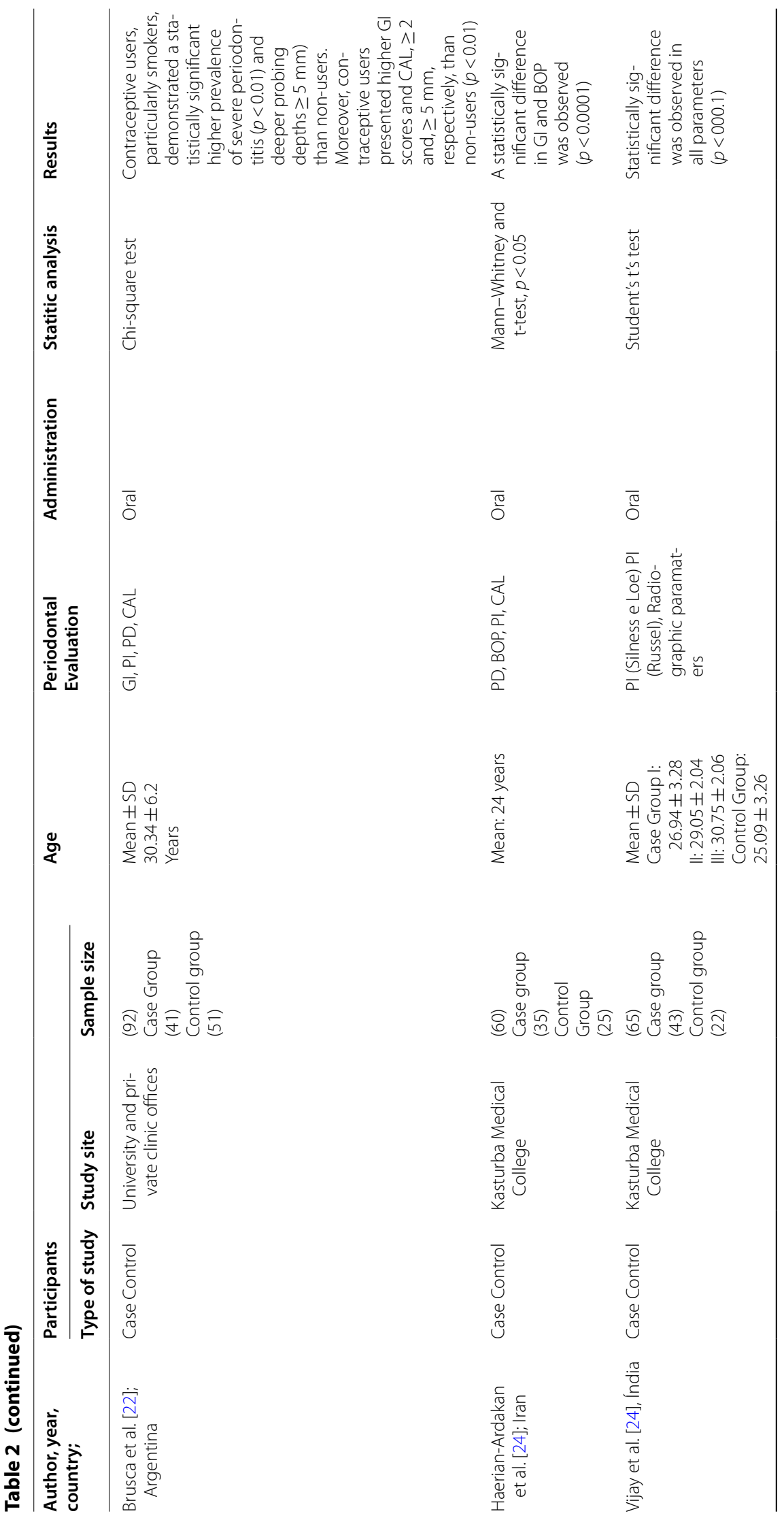




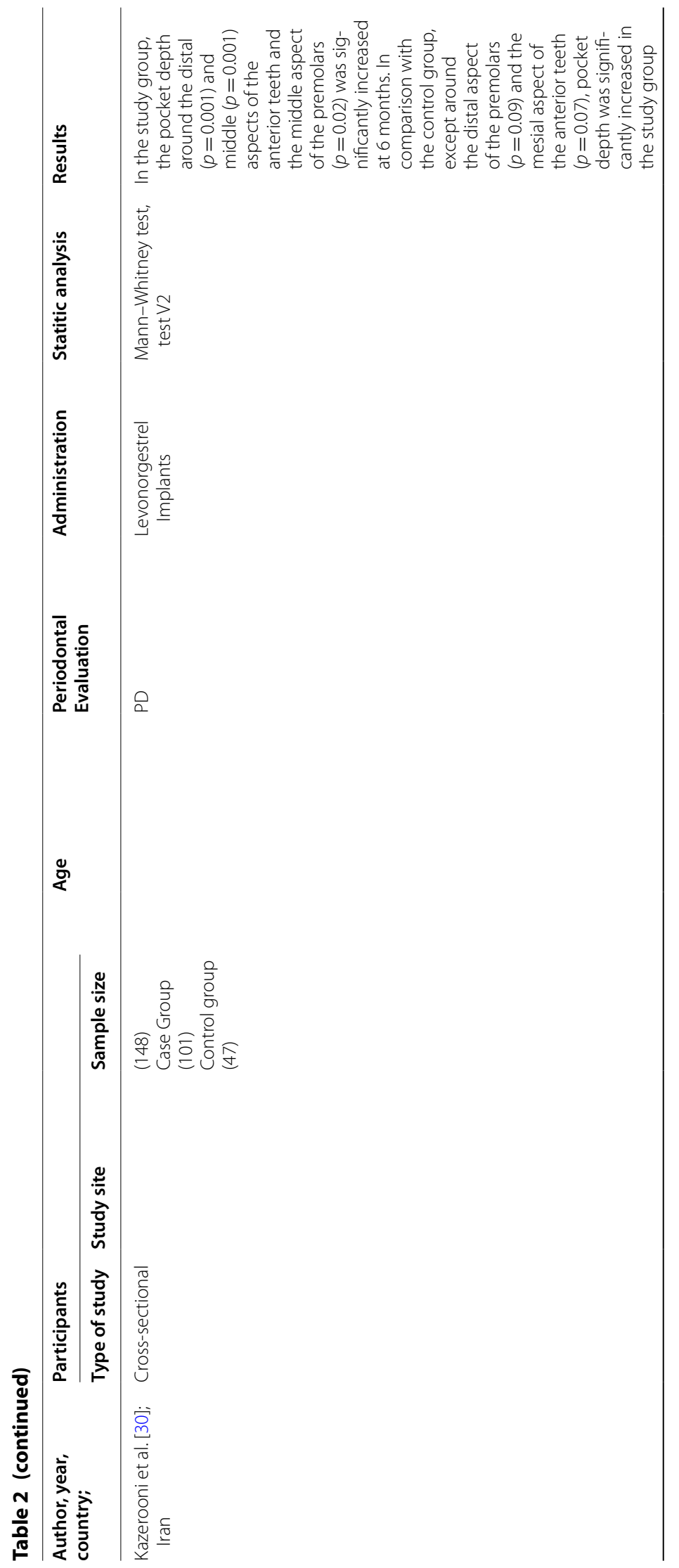




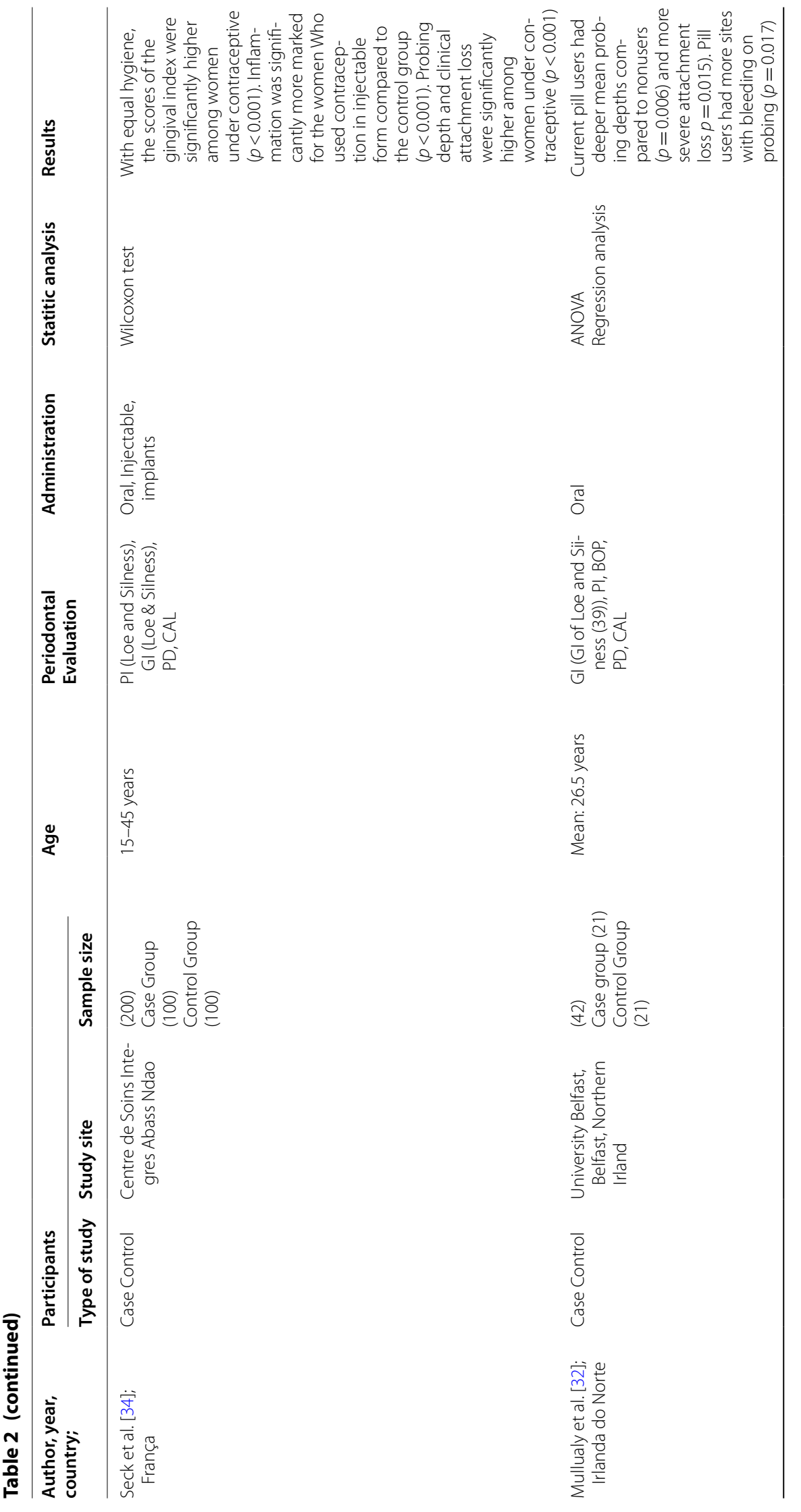




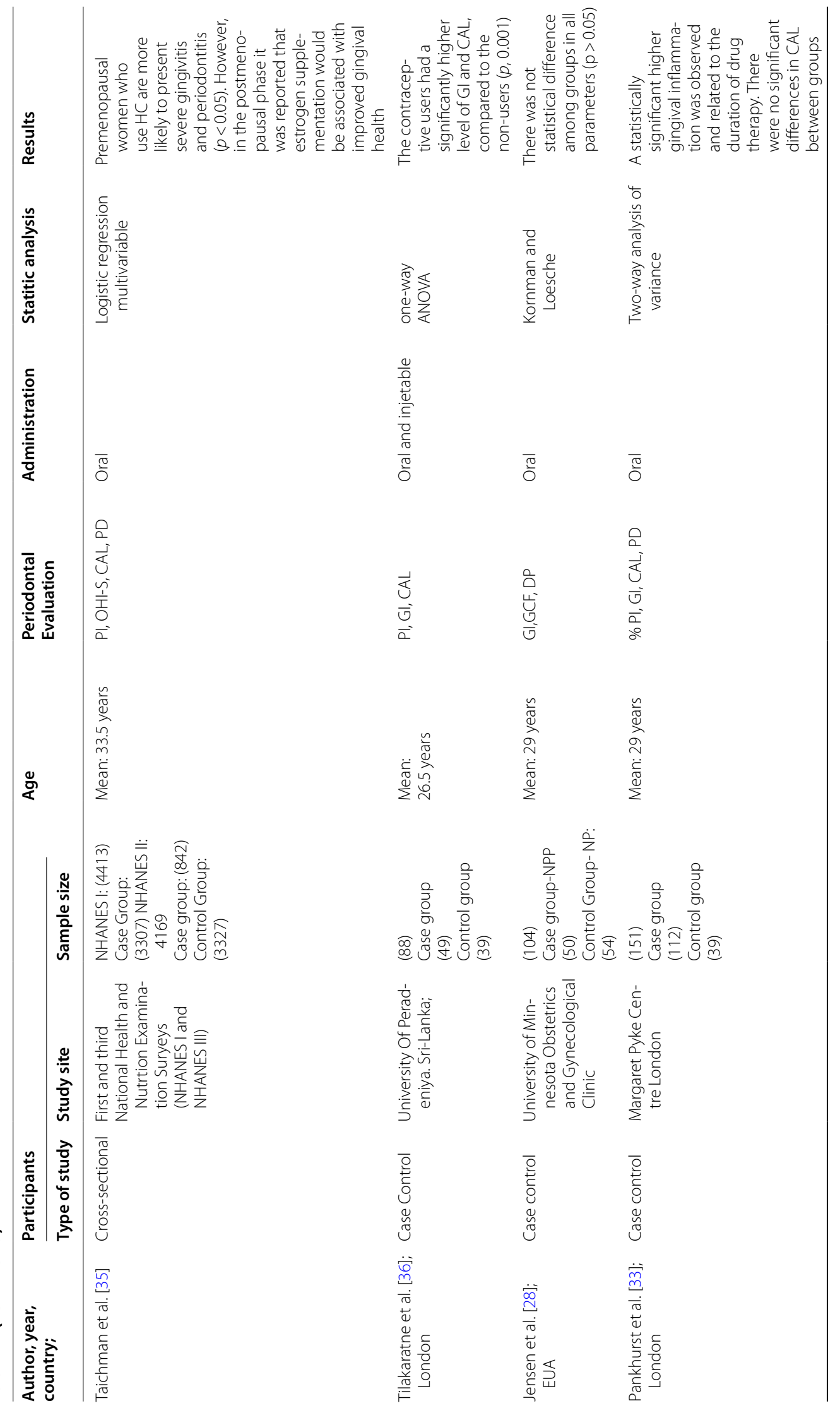




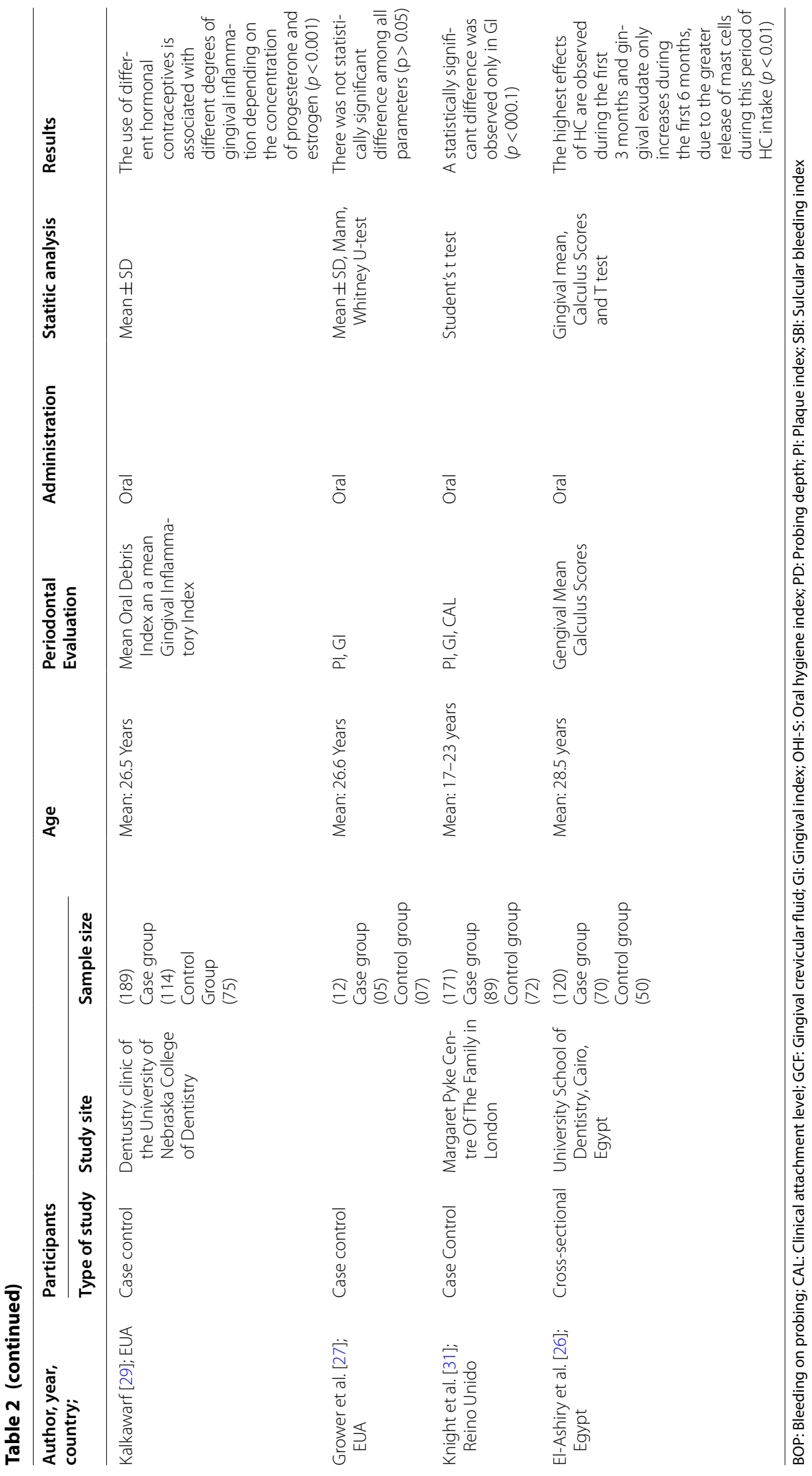




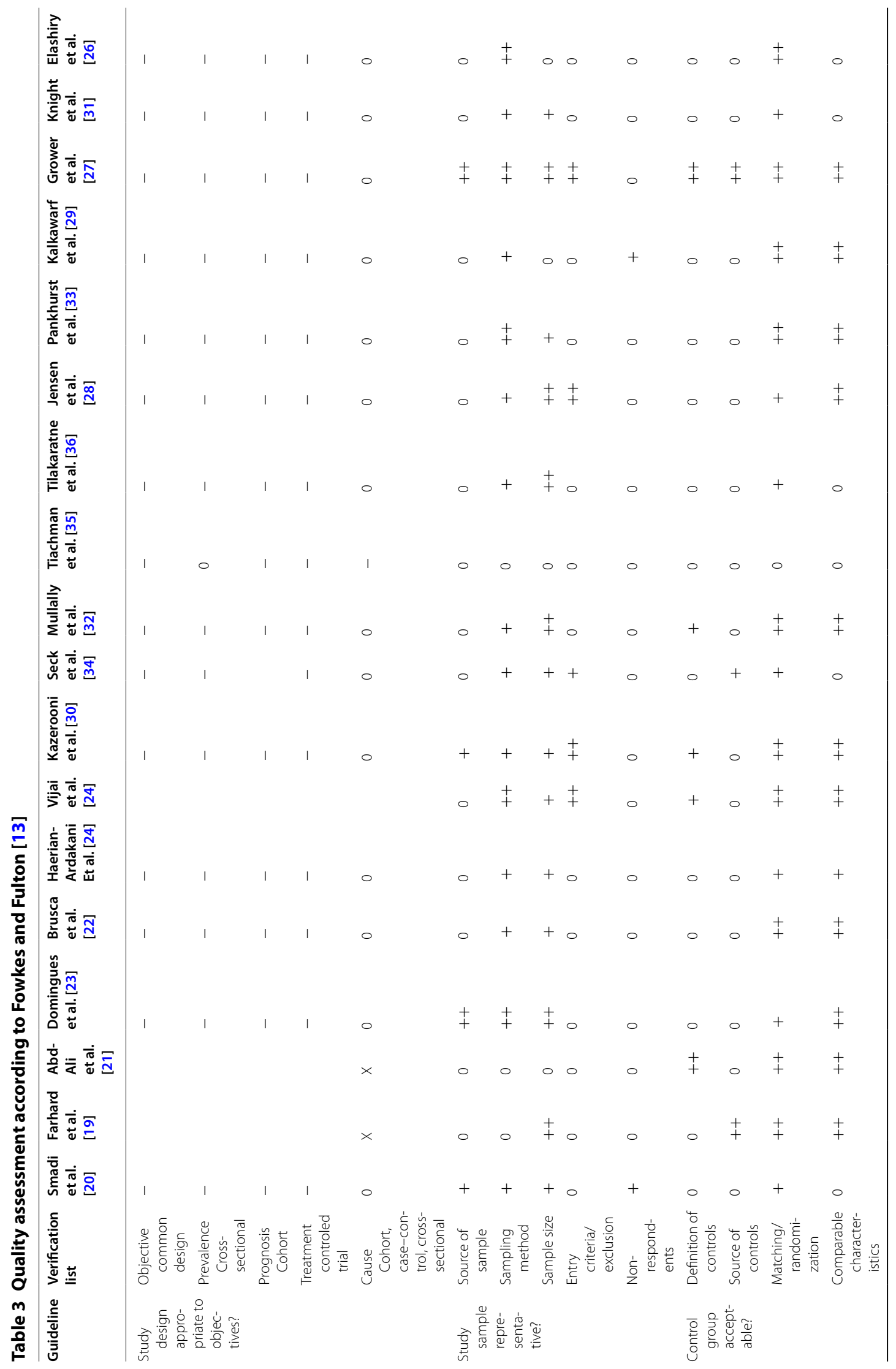




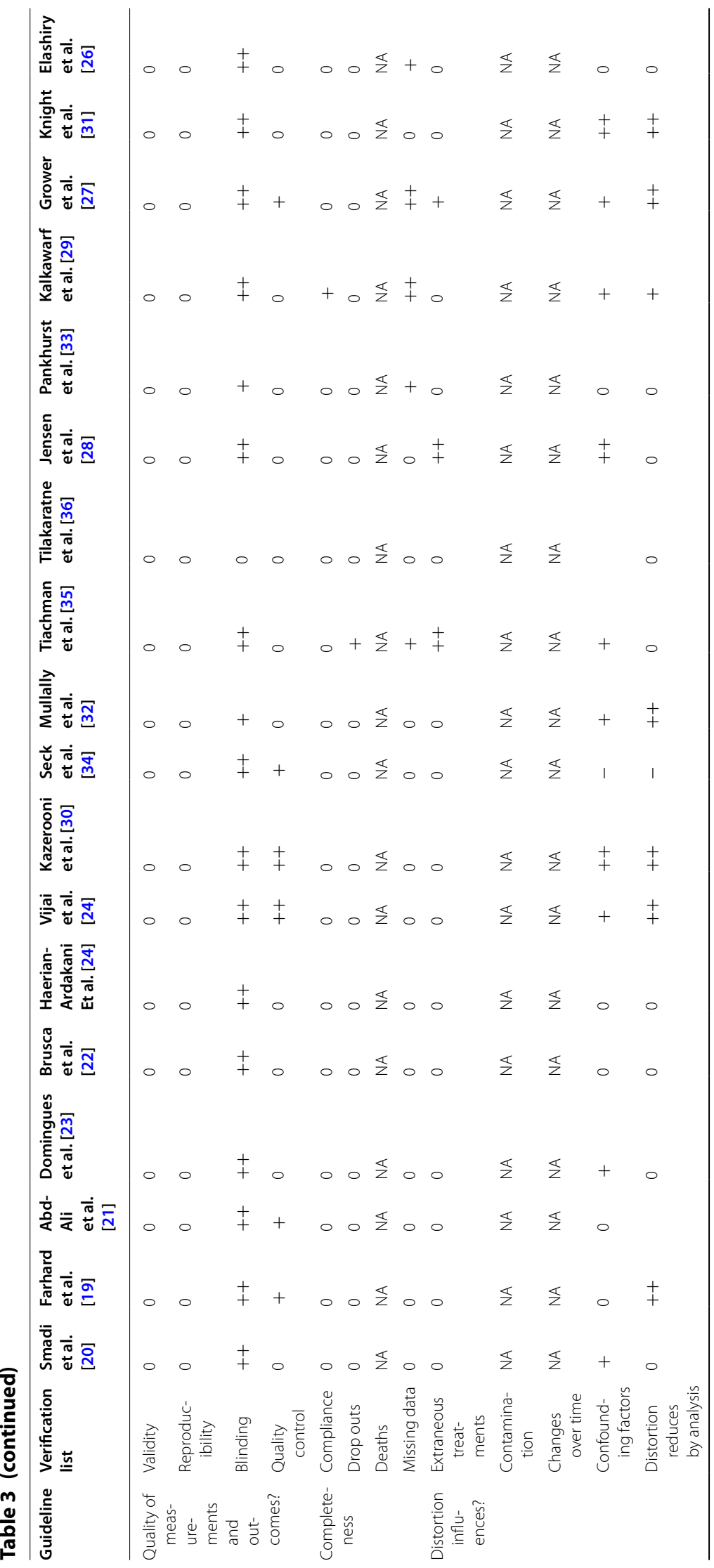




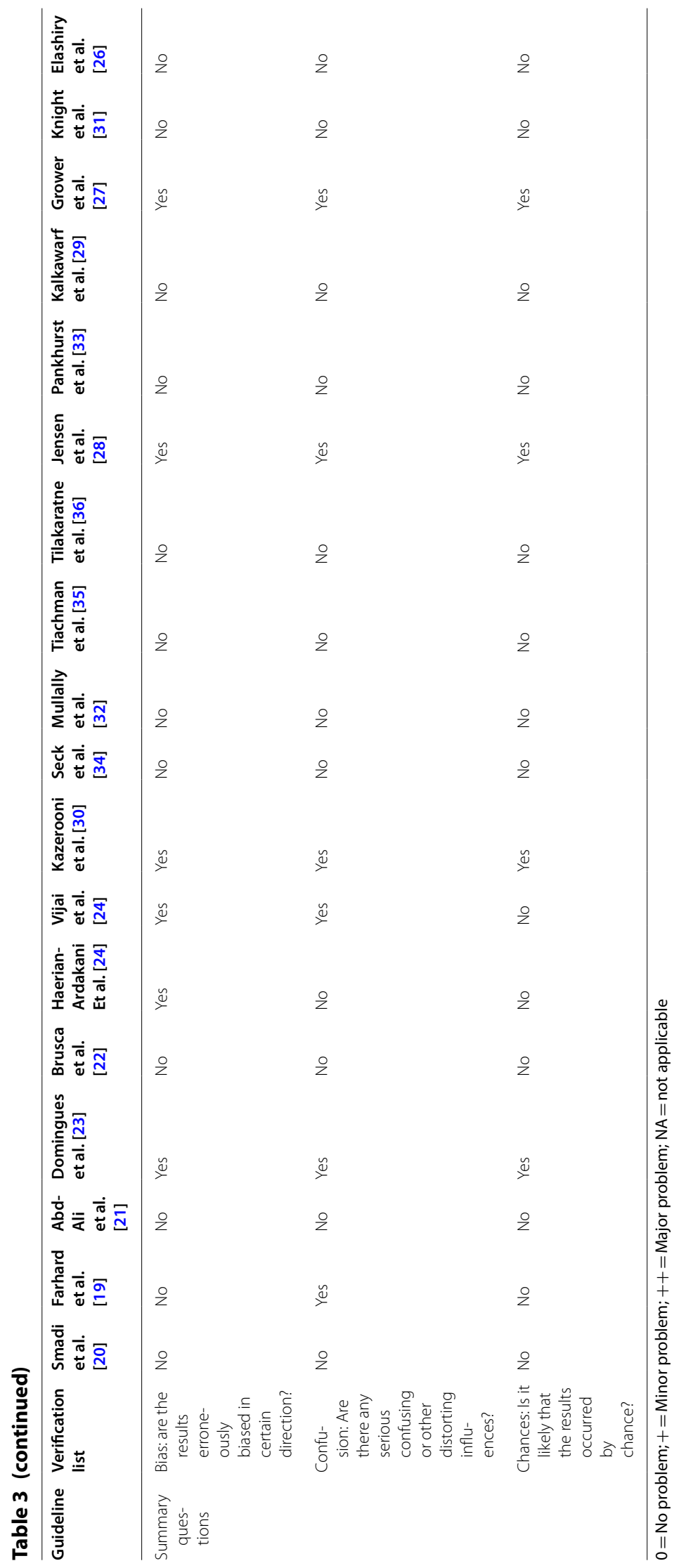




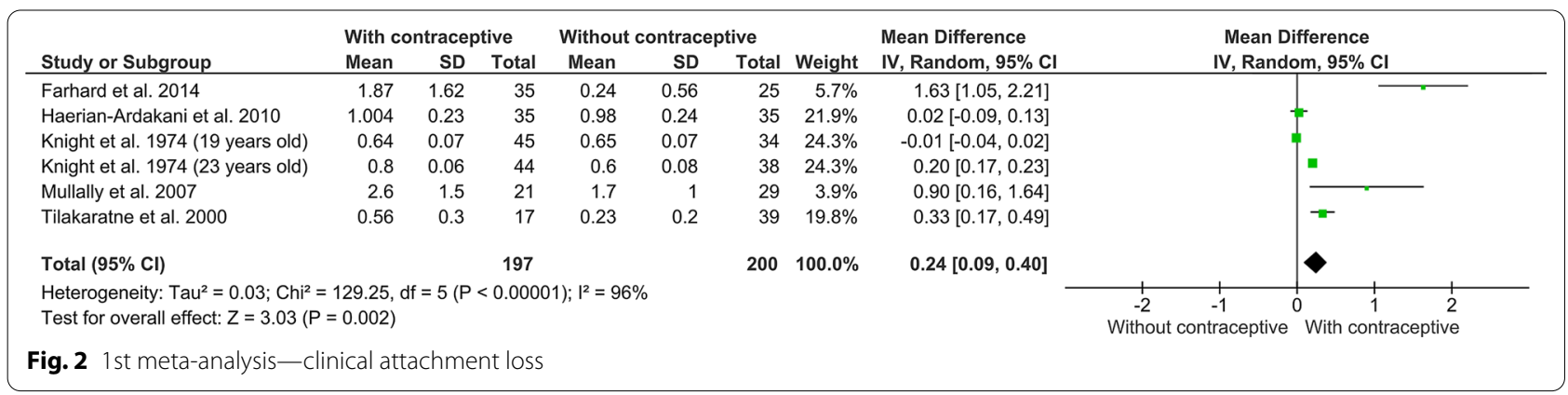

by Haerian-Ardakani et al. [24], which presented the greatest weight in our meta-analysis (Fig. 3). The inclusion of high risk of bias study change the significance of the effect (MD $0.56[0.22,0.91] p=0.001)$.

\section{Discussion}

The objective of this study was to evaluate the impact of the use of hormonal contraceptives on periodontal conditions. Then, a comparative analysis of users and nonusers of hormonal contraceptives was performed. In this sense, a systematic review with meta-analyses was performed using important databases of literature in health sciences. The topic under study is of high clinical interest [37], however, the information presented in literature comes from studies that present some concerns in methodological features or low degree of evidence.

As from de board search, 18 articles were included in this systematic review without restrictions for the type of hormonal contraceptives. Concerning the included studies, 15 pointed worse periodontal clinical parameters in contraceptive users [19-26, 29, 30, 32-36]. However, the quantitative analysis indicates a potentially inconclusive outcome due to the heterogeneity detected in the articles, also highlighted in the level of evidence analysis, consequently compromising the evaluation of this association with the possibility of a more in-depth risk approach.

In order to formulate the scientific research question, our systematic review used the PECO's strategy [38], which allows evaluating a potential risk or prognosis of contraceptive users to periodontal diseases, conditions characterized by the existence of a pathological inflammatory process in the periodontal structures (gums, cementum, periodontal ligament, and alveolar bone). Based on these cited premises, this systematic review and meta-analysis evaluates observational studies, mainly with cross-sectional design and case-control. Then, the results have the potential to generate information about greater or lesser odds of women using hormonal contraceptives present clinical manifestations of periodontal diseases. From this type of information, policies for the prevention of periodontal diseases could be proposed, both at the collective level (woman's health) and in a personalized dentistry approach.

All the included studies collected data from anamnesis and clinical measures as, for example, OHI-S, CAL, gingival index $(\mathrm{GI}), \mathrm{PD}$, plaque index (PI), bleeding on probing (BOP), Mean Debris Index, Gingival Mean and Calculus scores. Other studies performed radiographic complementary analysis [25] and laboratory analysis of gingival crevicular fluid [28]. These analyses allow not only evaluation of the inflammatory status of periodontal tissues (GI, PI, BOP, Gingival Mean, Calculus Scores) $[39,40]$, but also the analysis of loss of periodontal tissue support (PD, CAL) [16], and need for periodontal treatment (PI, OHI-S) [41]. However, it is important to emphasize that the wide range of the collected clinical parameters prevents data from being pooled and more specific conclusions drawn. Additionally, some parameters analyzed presented limitations according to the contemporary knowledge, for example, Russel's index and OHI-S.

Regarding the hormonal therapies with steroids and progesterone, most of them were hormonal oral administration, following by implanted devices and injectable contraceptives. Similarly to periodontal parameters, it is important to describe that hormonal contraceptives are quite variable. It is recognized in the contraception field, the evolution of the methods also has modified the prescriptions, and probably their adverse effects. It is known that efforts have been made to improve the effectiveness of contraception, with the reduction of hormonal load. This trend has the potential to minimize the adverse effects related to periodontal disease manifestations, especially in the function of the hormonal dosage, the probable cause of the adverse effect presented in this review.

Sex hormones are considered modifying factors, they are able to modulate the inflammatory response of tissues, including periodontal tissues. Studies indicate that gingival keratinocytes, gingival fibroblasts 


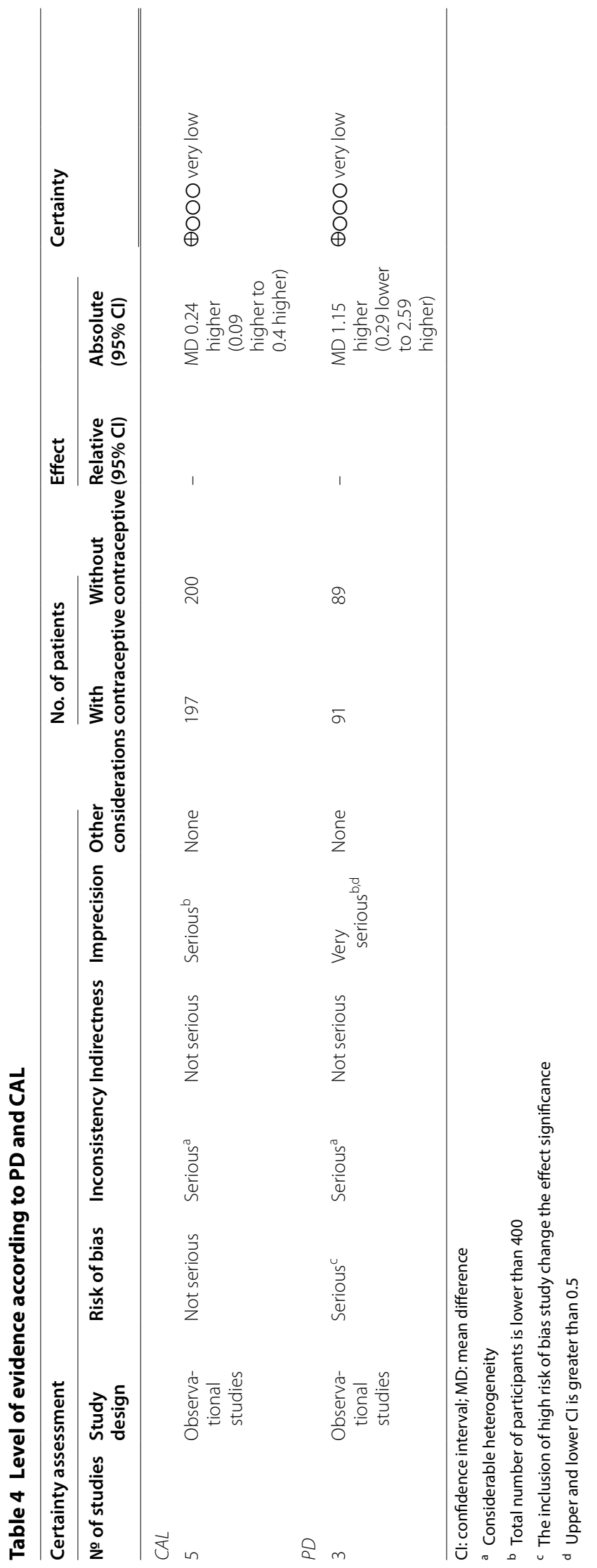




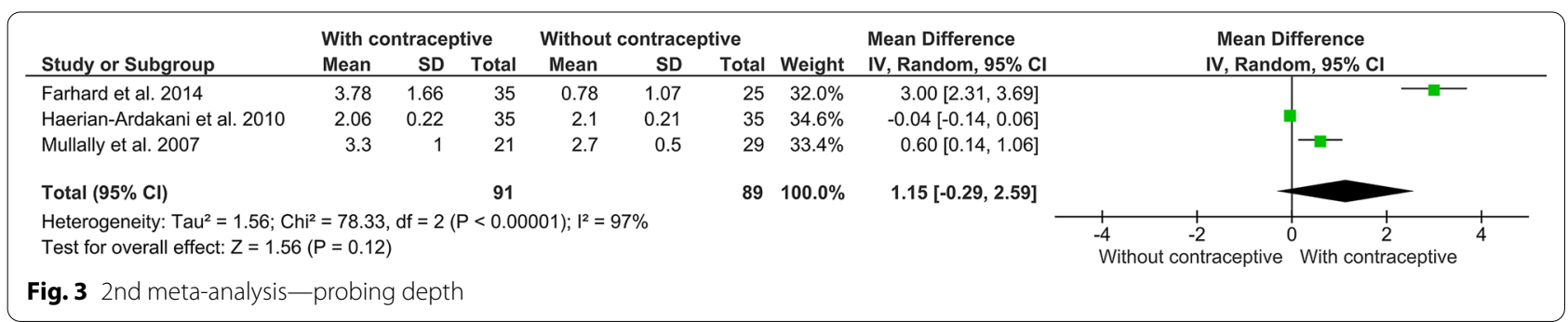

presented in the periodontal ligament, and in the lamina propria have receptors for sex hormones, such as estrogen and progesterone [42, 43]. Thus, steroid hormones are able to indirectly modulates periodontal tissue. Estrogen is able to modulate collagen metabolism and angiogenesis, in addition to promoting an increase in tissue glycogen production and reducing keratinization of the gingival epithelium, causing a reduction in the epithelial barrier. In addition, it modifies cell proliferation such as increased phagocytosis and reduced leukocyte production in the bone marrow. In particular, progesterone triggers vasodilation in blood vessels and consequently increases endothelial permeability, managing to alter the function of periodontal ligament fibroblasts in collagen production, inhibiting the synthesis of collagen and non-collagen proteins, reducing folate levels, which promotes an imbalance in tissue repair $[44,45]$.

Several studies also show the relationship between sex hormones and changes in the production of inflammatory cytokines such as tumor necrosis factor, which has been quite associated with periodontal disease, as well as the IL- 1 and IL-6, associated with bone resorption. In short, sex hormones promote a modulation of the host's response, such as increased vasodilation, vascular permeability, and inflammatory mediators, cytokines and prostaglandins, in the gingival tissue.

Although the studies have suitable clinical parameters to evaluate the use of contraceptives and also diagnose the periodontal diseases, the Fowkes and Fulton's guideline was used, with the objective of qualifying the methods adopted in the studies, enabling the sufficiency assessment of these methods. The quality analysis indicated problems related to the sample size $[19,20,22-25,27,28,30-33,36]$, suggesting the necessity of new studies with larger samples. The difficulties in carrying out population-based studies is well-known in the literature. Then, in the analytical perspective, at least the studies should include a large number of participants. The samples should be big enough for the probability of finding true statistically significant differences that demonstrate high clinical significance. However, this number should not be excessive, in order to avoid the waste of resources and the exposure of participants to unnecessary risk, for this in delineating these types of observational study it is necessary to have the presence of the realistic sample calculation [46].

In the quantitative analysis, it was sought to investigate the effect of hormonal contraceptives in CAL and PD clinical parameters. PD is a parameter that is associated with the inflammatory process. As inflammation increases, the probe penetrates more on the tissues. Moreover, CAL is related to the process of past periodontal destruction, in other words, how much periodontal tissue has already been lost as a result of inflammation. The combination of these two parameters is the gold standard for the evaluation of periodontal diseases. Recently, the new classification of periodontal diseases points to the necessity to exist a joint evaluation of these two parameters [47].

Despite the meta-analysis demonstrated the worst CAL in women users of contraceptives, PD data did not show a statistically significant difference. This information is amazing on the one hand, since lower rates of inflammation were observed. The possible explanation is because only one clinical examination was performed in most studies, without evaluation of longitudinality. On the other hand, the experience accumulated resulting from a persistent inflammatory process that was observed through the CAL with worse levels in the users of hormonal contraceptives. Furthermore, a few studies were included in the quantitative analysis, it could be contributed to this startling result. Currently, it is suggested that more parameters should be investigated to define the clinical picture of periodontitis. For severity, beyond CAL mensuration, the radiographic and quantification of tooth loss should be performed too. Moreover, for complexity, other parameters as furcation involvement, complex rehabilitation needs, the number of remaining teeth should be also analyzed.

Furthermore, the high heterogeneity presented among the included studies in meta-analysis indicated the presence of an impact in the validity of these results, this questioning was pointed in the certainty of the scientific evidence proposed by also the GRADE tool also. 
The term "heterogeneity" refers to de dispersion of true effect across studies $\left(\mathrm{I}^{2}\right)$ and the standard deviation between true effects $\left(\mathrm{Tau}^{2}\right)$. In the random effect-model, the standard errors of the studies are adjusted to incorporate a measure of the extent variation $\left(\mathrm{I}^{2}\right)$ among the the effect of the interventions observed in the studies $\left(\mathrm{Tau}^{2}\right)$ [48]. It must take into account that the study effect varies according to characteristics of its population (age), interventions (hormonal dose), possible confounding factors (systemic diseases, oral hygiene habits, etc.), and other parameters. Therefore, the studies estimate different, but related, interventions effect and these factors influence the $\mathrm{I}^{2}$. So, in the meta-analysis of the present systematic review a random-effect model was adopted.

Some studies included in this systematic review and meta-analysis have some limitations such as the different methods that were used to assess periodontal disease and others did not report the composition of the drug and/ or the dose/time used by the patients. Other important information is that the introduction of combined hormonal contraceptives with low dosage as the first pregnancy prevention option used in the last 30 years $[49,50]$. These medicines also have high efficacy as compared to high dose, and have better tolerability and fewer side effects [50]. In the present systematic review, there is a variability of performance in these studies, from 1971 (El-Shary [26]) to the year 2018 (Smadi et al. [20]), the use of different types of doses of oral hormonal contraceptives possibly contributed to different results in the summarized analyzes.

These steroid hormones not only are responsible for physiologic changes in different phases of a woman life, but also act in different organ systems, including the oral cavity $[51,52]$. The scientific literature complements that the periodontium is uncertain target tissue of these steroids' hormones, however, the biological meaning of this association is further clarified by the presence of receptors of these hormones in the periodontal tissues [53]. Thus, estrogen and progesterone levels present in the contraceptive's composition can modulate biological response [54]. Moreover, it is believed that the high level of these hormones acts in the vascular system, which can influence gingival inflammation [37]. Currently, the changes on general oral health in women using hormonal contraceptives were studied [55]. Ali et al. [11] corroborate with the outcomes found in this systematic review, that the changes in the periodontium are inconclusive.

In this sense, the monitoring and guidance by a professional in the dental field has great importance to control and treat the possible effects arising from the use of hormonal contraceptives in the oral cavity associated with the use of hormonal contraceptives. It is known that periodontal disease is associated with other comorbidities in the body, such as a reduction in the individual's immune response, making him more susceptible to other diseases [56]. In addition, improving the quality of life of women using hormonal contraceptives. Moreover, further studies are necessary to investigate the relationship of each type of pharmacological agent, dose, and time of administration to better elucidate this relation.

Despite the majority of the studies presents a low risk of bias individually, the summarized results pointed methodological failures that, if corrected in future studies, will allow better clinical and epidemiological evidence, for example, increase in sample size, an accomplishment of all clinical parameters pertinent to periodontitis, followup of patients over time, between others will be important for further investigation into this association.

\section{Conclusions}

The results observed in this review indicate a potential effect of hormonal contraceptives in the periodontium, but not allowing solid conclusions, and still does not allow the adoption of clear preventive measures related to the use of hormonal contraceptives and periodontal diseases.

\section{Supplementary Information}

The online version contains supplementary material available at https://doi. org/10.1186/s12905-021-01180-0.

Additional file 1. PRISMA Checklist.

Additional file 2. Search Strategies.

\section{Abbreviations}

BOP: Bleeding on probing; CAL: Clinical attachment loss; Cl: Confidence interval; Gl: Gingival index; GRADE: Grading of Recommendations Assessment, Development, and Evaluation; PI: Plaque index; PRISMA: Preferred Reporting Items for Systematic Reviews and Meta-Analyses; PD: Probing depth; SMD: Standard mean difference.

\section{Acknowledgements}

The authors would like to thank the Federal University of Pará, Federal University of Rio de Janeiro and Federal University of Rio Grande do Sul for technical and scientific support.

\section{Authors' contributions}

MMLC and LCP were involved in the conception and design of the study. MMLC and MKMF, performed the searches, quality assessment, analysis of results supported by RRL and LCP. MMLC, PBON, and IEP performed data extraction, analysis of results. MBM, LCM and CKR performed quantitative analysis. MMLC was responsible for writing the article and CKR and RRL were responsible for revising it critically for important intelectual contente. All authors have read, revised, and approved the final manuscript.

\section{Funding}

This work was supported by Research Pro-Rectory of Federal University of Pará (PROPESP, UFPA, Brazil), Brazilian National Council for Scientific and Technological Development (CNPq), Support Research Foundation from State of Pará (FAPESPA) and Coordination for the Improvement of Higher Education Personnel_Brazil (CAPES)_Finance Cod 001 and Programa Nacional de Cooperação Acadêmica na Amazônia—PROCAD/Amazônia/CAPES. The funders had no 
role in the study design, data extraction and analysis, decision to publish, or preparation of the manuscript.

\section{Availability of data and materials}

The datasets analyzed during the current study are available from the corresponding author on reasonable request.

\section{Ethics approval and consent to participate}

Not applicable. Ethical approval was not required for this paper as it is a systematic review and meta-analysis of existing published qualitative research.

\section{Consent for publication}

Not applicable.

\section{Competing interests}

The authors declare that they have no competing interests.

\section{Author details}

${ }^{1}$ Laboratory of Functional and Structural Biology, Institute of Biological Sciences, Federal University of Pará, Augusto Corrêa street, n 1, Guamá, Belém PA 66075-110, Brazil. ${ }^{2}$ Department of Pediatric Dentistry and Orthodontics, School of Dentistry, Federal University of Rio de Janeiro, Rio de Janeiro, Brazil. ${ }^{3}$ Department of Periodontology, Faculty of Dentistry, Federal University of Rio Grande do Sul, Porto Alegre, Brazil.

Received: 27 December 2019 Accepted: 13 January 2021 Published online: 01 February 2021

\section{References}

1. Colquitt CW, Martin TS. Contraceptive methods. J Pharm Pract. 2017;30(1):130-5.

2. Uhm S, Perriera L. Hormonal contraception as treatment for heavy menstrual bleeding: a systematic review. Clin Obstet Gynecol. 2014;57(4):694-717.

3. Rivera R, Yacobson I, Grimes D. The mechanism of action of hormonal contraceptives and intrauterine contraceptive devices. Am J Obstet Gynecol. 1999;181(5 Pt 1):1263-9.

4. Allan GM, Koppula S. Risks of venous thromboembolism with various hormonal contraceptives. Can Fam Physician. 2012;58(10):1097.

5. J GC, Armitage G, Berglundh T, Chapple ILC, Jepsen S, K SK, et al. A new classification scheme for periodontal and peri-implant diseases and conditions - Introduction and key changes from the 1999 classification. J Clin Periodontol. 2018;45 Suppl 20:S1-s8.

6. Chapple ILC, Mealey BL, Van Dyke TE, Bartold PM, Dommisch H, Eickholz $P$, et al. Periodontal health and gingival diseases and conditions on an intact and a reduced periodontium: Consensus report of workgroup 1 of the 2017 World Workshop on the Classification of Periodontal and PeriImplant Diseases and Conditions. J Periodontol. 2018;89(Suppl 1):S74-s84.

7. Barber DN. Oral contraceptives and dental care. BMJ. 1967;4(5576):417.

8. D'Arco F, Passali D. Oral side effects of contraceptives. VALSALVA. 1975:51(1):23-32.

9. Duxbury AJ, Leach FN. Oral contraceptives and the dental practitioner. Dental update. 1982;9(2):97-9.

10. Heasman PA, Hughes FJ. Drugs, medications and periodontal disease. $\mathrm{Br}$ Dent J. 2014:217(8):411-9.

11. Ali I, Patthi B, Singla A, Gupta R, Dhama K, Niraj LK, et al. Oral health and oral contraceptive - is it a shadow behind broad day light? A Systematic Review. J Clin Diagnost Res JCDR. 2016;10(11):Ze01-ze6.

12. Moher D, Liberati A, Tetzlaff J, Altman DG. Preferred reporting items for systematic reviews and meta-analyses: the PRISMA statement. PLoS Med. 2009;6(7):e1000097.

13. Fowkes FG, Fulton PM. Critical appraisal of published research: introductory guidelines. BMJ. 1991;302(6785):1136-40.

14. Higgins JP, Altman DG, Gotzsche PC, Juni P, Moher D, Oxman AD, et al. The Cochrane Collaboration's tool for assessing risk of bias in randomised trials. BMJ. 2011;343:d5928.

15. Rosenblad A. Introduction to meta-analysis by Michael Borenstein, Larry V. Hedges, Julian P.T. Higgins, Hannah R. Rothstein2009. 478-9 p.
16. Lindhe J, Socransky SS, Nyman S, Haffajee A, Westfelt E. "Critical probing depths" in periodontal therapy. J Clin Periodontol. 1982;9(4):323-36.

17. Papapanou PN, Sanz M, Buduneli N, Dietrich T, Feres M, Fine DH, et al. Periodontitis: consensus report of workgroup 2 of the 2017 World Workshop on the Classification of Periodontal and Peri-Implant Diseases and Conditions. J Periodontol. 2018;89(Suppl 1):S173-82.

18. Balshem H, Helfand M, Schunemann HJ, Oxman AD, Kunz R, Brozek J, et al. GRADE guidelines: 3. Rating the quality of evidence. J Clin Epidemiol. 2011:64(4):401-6.

19. Farhad S, Esfahanian V, Mafi M, Farkhani N, Ghafari M, Sadighi M, et al. Asso2017 ciation between Oral Contraceptive Use and Interleukin-6 Levels and Periodontal Health 2014. 13-7 p.

20. Smadi L, Zakaryia A. The association between the use of new oral contraceptive pills and periodontal health: a matched case-control study. J Int Oral Health. 2018;10(3):127-31.

21. Shaker NT, Abd-Ali EH. The effect of oral contraceptive on the oral health with the evaluation of Salivary lgA and Streptococcus Mutans in some Iraqi women. Mustansiria Dent J. 2013;10(1):52-63.

22. Brusca MI, Rosa A, Albaina O, Moragues MD, Verdugo F, Ponton J. The impact of oral contraceptives on women's periodontal health and the subgingival occurrence of aggressive periodontopathogens and candida species. J Periodontol. 2010;81(7):1010-8.

23. Domingues RS, Ferraz BF, Greghi SL, Rezende ML, Passanezi E, Sant'Ana AC. Influence of combined oral contraceptives on the periodontal condition. J Appl Oral Sci. 2012;20(2):253-9.

24. Haerian-Ardakani A, Moeintaghavi A, Talebi-Ardakani MR, Sohrabi K, Bahmani S, Dargahi M. The association between current low-dose oral contraceptive pills and periodontal health: a matched-case-control study. J Contemp Dent Pract. 2010;11(3):033-40.

25. Vijay G. Relationship of duration of oral contraceptive therapy on human periodontium-A clinical, radiological and biochemical study. Ind J Dent Adv. 2010;2(2):168-74.

26. el-Ashiry GM, el-Kafrawy AH, Nasr MF, Younis N. Effects of oral contraceptives on the gingiva. J Periodontol. 1971;42(5):273-5.

27. Grower MF, Lyon DR, Levin MP, Chandler DW. Cyclic AMP content of gingival fluid in women taking oral contraceptives. J Oral Pathol. 1975;4(6):291-6.

28. Jensen J, Liljemark W, Bloomquist C. The effect of female sex hormones on subgingival plaque. J Periodontol. 1981;52(10):599-602.

29. Kalkwarf KL. Effect of oral contraceptive therapy on gingival inflammation in humans. J Periodontol. 1978;49(11):560-3.

30. Kazerooni T, Ghaffarpasand F, Rastegar N, Kazerooni Y. Effect of levonorgestrel implants on the periodontium. Int J Gynaecol Obstet. 2008;103(3):255-6.

31. Knight GM, Wade AB. The effects of hormonal contraceptives on the human periodontium. J Periodontal Res. 1974;9(1):18-22.

32. Mullally BH, Coulter WA, Hutchinson JD, Clarke HA. Current oral contraceptive status and periodontitis in young adults. J Periodontol. 2007;78(6):1031-6.

33. Pankhurst CL, Waite IM, Hicks KA, Allen Y, Harkness RD. The influence of oral contraceptive therapy on the periodontium - duration of drug therapy. J Periodontol. 1981;52(10):617-20.

34. Seck-Diallo A, Cissé ML, Benoist HM, Diouf A, Ahnoux-Kouadio A, Diallo $\mathrm{T}$, et al. Periodontal status in a sample of Senegalese women using hormonal contraception. Odonto-stomatologie tropicale = Trop Dent J. 2008;31(121):36-42.

35. Taichman LS, Eklund SA. Oral contraceptives and periodontal diseases: rethinking the association based upon analysis of National Health and Nutrition Examination Survey data. J Periodontol. 2005;76(8):1374-85.

36. Tilakaratne A, Soory M, Ranasinghe AW, Corea SMX, Ekanayake SL, De Silva M. Effects of hormonal contraceptives on the periodontium, in a population of rural Sri-Lankan women. J Clin Periodontol. 2000;27(10):753-7.

37. Preshaw PM. Oral contraceptives and the periodontium. Periodontology 2000. 2013;61(1):125-59.

38. Richardson WS, Wilson MC, Nishikawa J, Hayward RS. The well-built clinical question: a key to evidence-based decisions. ACP J Club. 1995;123(3):A12-3.

39. Loe $H$. The Gingival Index, the Plaque Index and the Retention Index Systems. J Periodontol. 1967;38(6):Suppl:610-6. 
40. Lang NP, Joss A, Orsanic T, Gusberti FA, Siegrist BE. Bleeding on probing. A predictor for the progression of periodontal disease? J Clin Periodontol. 1986;13(6):590-6.

41. Lang NP, Tonetti MS. Periodontal diagnosis in treated periodontitis. Why, when and how to use clinical parameters. J Clin Periodontol. 1996;23(3 Pt 2):240-50.

42. Eriksen EF, Colvard DS, Berg NJ, Graham ML, Mann KG, Spelsberg TC, et al. Evidence of estrogen receptors in normal human osteoblast-like cells. Science. 1988:241(4861):84-6.

43. Komm BS, Terpening CM, Benz DJ, Graeme KA, Gallegos A, Korc M, et al. Estrogen binding, receptor $\mathrm{mRNA}$, and biologic response in osteoblastlike osteosarcoma cells. Science. 1988;241(4861):81-4.

44. Lapp CA, Thomas ME, Lewis JB. Modulation by progesterone of interleukin-6 production by gingival fibroblasts. J Periodontol. 1995;66(4):279-84.

45. Markou E, Boura E, Tsalikis L, Deligianidis A, Konstantinidis A. The influence of sex hormones on proinflammatory cytokines in gingiva of periodontally healthy premenopausal women. J Periodontal Res. 2011;46(5):528-32.

46. Ebrahim Valojerdi A, Tanha K, Janani L. Important considerations in calculating and reporting of sample size in randomized controlled trials. Med $J$ Islamic Republic of Iran. 2017;31:127.

47. Tonetti MS, Greenwell H, Kornman KS. Staging and grading of periodontitis: framework and proposal of a new classification and case definition. J Periodontol. 2018;89(Suppl 1):S159-72.

48. Borenstein M. Common mistakes in meta-analysis and how to avoid them: Biostat, Incorporated; 2019.

49. Baillargeon JP, McClish DK, Essah PA, Nestler JE. Association between the current use of low-dose oral contraceptives and cardiovascular arterial disease: a meta-analysis. J Clin Endocrinol Metab. 2005;90(7):3863-70.
50. Schwartz SM, Siscovick DS, Longstreth Jr W, Psaty BM, Beverly RK, Raghunathan T, et al. Use of low-dose oral contraceptives and stroke in young women. Ann Internal Med. 1997;127(8_Part_1):596-603.

51. Campbell SE, Febbraio MA. Effect of ovarian hormones on mitochondrial enzyme activity in the fat oxidation pathway of skeletal muscle. Am J Physiol Endocrinol Metab. 2001;281 (4):E803-8.

52. D'Eon TM, Sharoff C, Chipkin SR, Grow D, Ruby BC, Braun B. Regulation of exercise carbohydrate metabolism by estrogen and progesterone in women. Am J Physiol Endocrinol Metab. 2002;283(5):E1046-55.

53. Markou E, Eleana B, Lazaros T, Antonios K. The influence of sex steroid hormones on gingiva of women. Open Dent J. 2009;3:114-9.

54. Bergqvist A, Bergqvist D, Fernö M. Estrogen and progesterone receptors in vessel walls: biochemical and immunochemical assays. Acta Obstet Gynecol Scand. 1993;72(1):10-6.

55. Patil SN, Kalburgi NB, Koregol AC, Warad SB, Patil S, Ugale MS. Female sex hormones and periodontal health-awareness among gynaecologists-a questionnaire survey. Saudi Dent J. 2012;24(2):99-104.

56. Darby IB, Mooney J, Kinane DF. Changes in subgingival microflora and humoral immune response following periodontal therapy. J Clin Periodontol. 2001;28(8):796-805.

\section{Publisher's Note}

Springer Nature remains neutral with regard to jurisdictional claims in published maps and institutional affiliations.

Ready to submit your research? Choose BMC and benefit from:

- fast, convenient online submission

- thorough peer review by experienced researchers in your field

- rapid publication on acceptance

- support for research data, including large and complex data types

- gold Open Access which fosters wider collaboration and increased citations

- maximum visibility for your research: over $100 \mathrm{M}$ website views per year

At BMC, research is always in progress.

Learn more biomedcentral.com/submissions 